\title{
A case of Tinea nigra associated to a bite from a European rabbit (Oryctolagus cuniculus, Leporidae): the role of dermoscopy in diagnosis
}

\author{
André Luiz Rossetto ${ }^{1}$ \\ Eduardo Figueiredo Pereira ${ }^{1}$
}

\author{
Patricia Rossetto Corrêa ${ }^{2}$ \\ Vidal Haddad Junior ${ }^{4}$
}

Rosana Cé Bella Cruz ${ }^{3}$

Abstract: We report a case of Tinea nigra in an adolescent living in Itapema, Santa Catarina, Brazil, who presented a hyperchromic macule on the palm of the left hand, close to another erythematous macule caused by a rabbit bite. The patient received guidance on accidents and animal bites and evolved well treated with topical butenafine for the dermatomycosis. The authors also highlight the efficacy of the dermoscopic exam in diagnosing Tinea nigra with animal bite lesions and other traumas.

Keywords: Bites and stings; Dermatomycoses; Dermoscopy; Mycoses; Tinea

Tinea nigra (TN) manifests as an asymptomatic hyperchromic macule in the palmar region, and eventually the plantar or other atypical areas..$^{1-5}$ Dermoscopy exam reveals its unique characteristic pattern, but aetiology is established by the mycologic examination. ${ }^{6-}$ ${ }^{9}$ Treatment response is good to topical antifungals with reports of spontaneous cure. ${ }^{2-6}$

The patient was a thirteen year old female with two asymptomatic marks measuring $1.0 \times 2.0 \mathrm{~cm}$ in the left palmar region, one black spotted and the other erythematous, of geographic shape and scaly border, caused by a European rabbit (Oryctolagus cuniculus) bite while playing with the animal (Figure 1).

Dermoscopy of the hyperchromic macule showed darkened irregular puntiform pigmentation, a pattern typical to TN (Figure 2). The erythematous macule had a red homogenous colour without red spots or crown (Figure 3). In both there was an

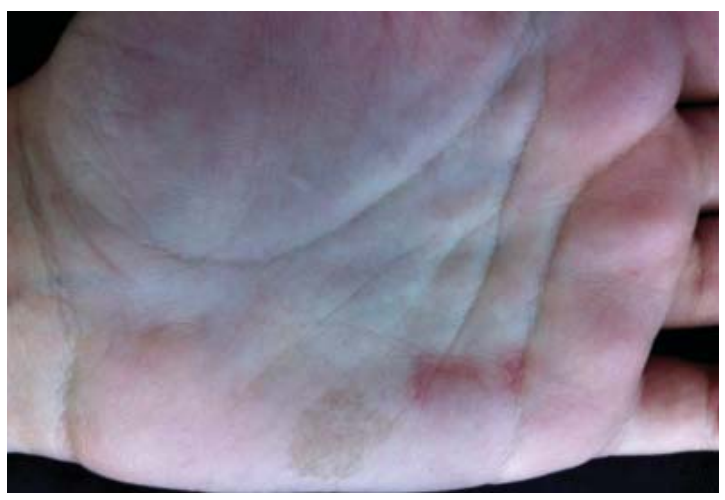

FIGURE 1: Detail of two macules, both sized approximately $1.0 \times 2.0$ $\mathrm{cm}$ and located on the internal edge of the left palmar region, one black spotted and not scaly, and one erythematous of geographic shape, poorly delimited borders, and with discrete scaling on the distal border

Received on 13.02.2013.

Approved by the Advisory Board and accepted for publication on 15.04.2013.

Work performed at the Dermatology Outpatient Clinic, Vale do Itajaí University (Univali) - Itajaí, SC, Brazil.

Conflict of interest: None

Financial funding: None

Dermatologist, Professor of Dermatology, Vale do Itajaí University (Univali) - Itajaí, SC, Brazil.

Medical Academic, Marilia University (Unimar) - Marília, SP, Brazil.

Masters in Pharmaceutical Biochemistry, Vale do Itajaí University (Univali) - Itajaí, SC, Brazil.

Dermatologist, Associate Professor, Botucatu School of Medicine, Universidade Estadual Paulista (UNESP) - São Paulo, SP, Brazil. 


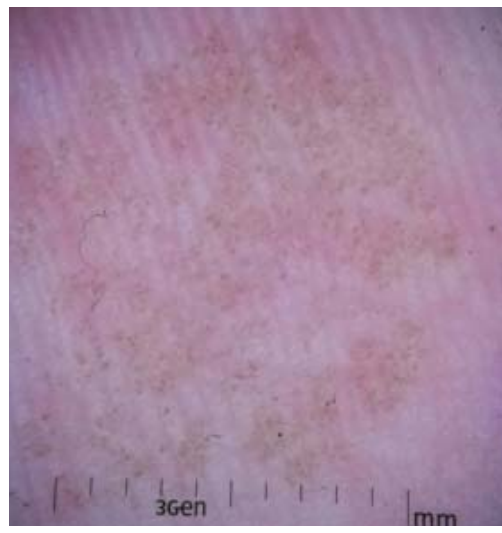

Figure 2:

Dermoscopy of the hyperchromic macule showed darkened pigmentation, distributed in an irregular spotty shape without the standard characteristics of melanocytic pigmented lesions such as pigment network, globules, and stripes.

(Magnification 10x)

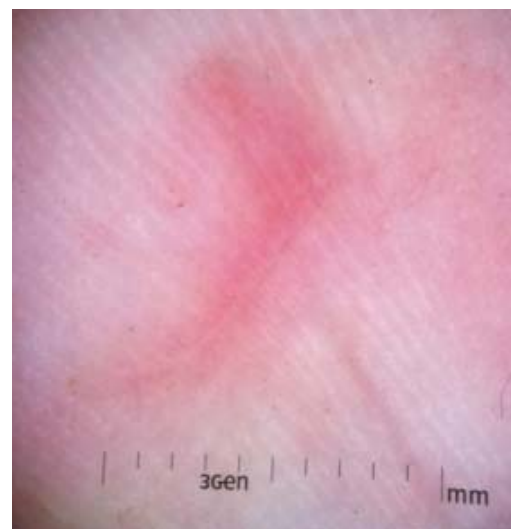

Figure 3:

Dermoscopy of the erythematous macule showing an area of reddened homogenous regularly distributed colouration with imprecise limits, an absence of red spots crown. (Magnification 10x)

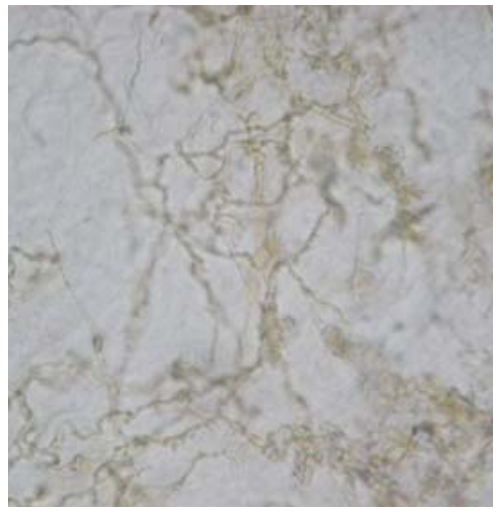

FIGURE 4:

Mycological exam cleared with $20 \%$ potassium hydroxide, showing irregular septate and ramified dematiaceous hyphae.

absence of typical pigmented melanocyte characteristics such as pigment network, globules, and stripes. The images were captured with a DermLite DL13Gen connected in a 5 megapixels iPhone $4 \mathrm{~S}$ camera.

Mycological exam of the hyperchromic macule revealed septate ramified dematiaceous hyphae (Figure 4). In Sabouraud Agar culture, wrinkled pigmented colonies were grown and $H$. werneckii was identified in microculture. The macule regressed after application of topical butenafine twice a day for four weeks with no recurrence in six months.

Dermascopy in TN, initially described in 1997 , is a simple conclusive examination which was effective in this case. ${ }^{6-10}$ The growing habit of keeping animals such as rabbits can occasionally lead to accidental bites and the resulting cutaneous lesion could be confused with TN.]

\section{REFERENCES}

1. Zaitz C, Campbell I, Marques AS, Ruiz LRB, Framil VMS. Dermatomicoses por fungos filamentosos septados demácios. In: Zaitz C, Campbell I, Marques SA, Ruiz LRB, Framil VMS. Compêndio de Micologia Médica. 2. ed. Rio de Janeiro: Guanabara Koogan, 2010. p. 180-6.

2. Rossetto AL, Cruz RC, Haddad Junior V. Double-blind study with the topical isoconazole and terbinafine for the treatment of one patient bilateral Tinea nigra plantaris and suggestions for new differential diagnoses. Rev Inst Med Trop Sao Paulo. 2013;55:125-8.

3. Rossetto AL, Cruz RCB. Tinea nigra in geographical forms of "heart" and "parrot beak". An Bras Dermatol. 2011;86:389-90.

4. Rossetto AL, Cruz RC. Tinea nigra: successful treatment with topical butenafine. An Bras Dermatol. 2012;87:939-41.

5. Rossetto AL, Cruz RCB. Spontaneous cure in a case of tinea nigra. An Bras Dermatol. 2012;87:160-2.

6. Bonifaz A, Badali H, de Hoog GS, Cruz M, Araiza J, Cruz MA, et al. Tinea nigra by Hortaea werneckii, a report of 22 cases from Mexico. Stud Mycol. 2008;61:77-82.

7. Xavier MH, Ribeiro LH, Duarte H, Saraça G, Souza AC. Dermatoscopy in the diagnosis of tinea nigra. Dermatol Online J. 2008:14:15.

8. Paschoal FM, de Barros JA, de Barros DP, de Barros JC, Filho CD. Study of the Dermatoscopic Pattern of Tinea Nigra: Report of 6 Cases. Skinmed. 2010;8:319-21.
9. Piliouras P, Allison S, Rosendahl C, Buettner PG, Weedon D. Dermoscopy improves diagnosis of tinea nigra: A study of 50 cases. Australas J Dermatol. 2011;52:191-4.

10. Gupta G, Burden AD, Shankland GS, Fallowfield ME, Richardson MD. Tinea nigra secondary to Exophiala werneckii responding to itraconazole. $\mathrm{Br} J$ Dermatol. 1997;137:483-4.

\section{MAILING ADDRESS:}

André Luiz Rossetto

Av. Alvin Bauer, 655 - Sala 203 - Vida Centro Médico 88330-643 - Balneário Camboriú - SC

Brazil

Email: rossettovida@terra.com.br

How to cite this article: Rossetto AL, Corrêa PR, Cruz RCB, Pereira EF, Haddad V Jr. A case of Tinea nigra associated to an accidental bite from a European rabbit (Oryctolagus cuniculus, Leporidae): the role of dermoscopy in diagnosis. An Bras Dermatol. 2014;89(1):163-4. 